(c) $(1) \Theta$

\title{
FORMAÇÃO CONTINUADA DE PROFESSORES EM SERVIÇO: OBSERVAÇÕES EM INSTITUIÇÕES PÚBLICAS DE UBERABA - MG
}

\author{
CONTINUED TRAINING OF TEACHERS IN SERVICE: OBSERVATIONS IN PUBLIC \\ INSTITUTIONS OF UBERABA - MG
}
FORMACIÓN CONTINUADA DE PROFESORES EN SERVICIO: OBSERVACIONES EN INSTITUCIONES PÚBLICAS DE UBERABA - MG

Simone das Graças Leal

E-mail: simonegracasleal@gmail.com

Helena de Ornellas Sivieri Pereira

E-mail: helena.sivieri@gmail.com

Universidade Federal do Triângulo Mineiro - UFTM

Maria Célia Borges

E-mail: marcelbor@gmail.com

Universidade Federal de Uberlândia - UFU

\section{RESUMO}

As propostas de formação continuada para os docentes têm sido uma preocupação tanto para o poder público, como para pesquisadores e teóricos da educação. O presente projeto tem como objetivo verificar a eficácia da formação continuada em serviço em termos de avanços conceituais na constituição da identidade e nas práticas dos professores da Educação Básica de escolas públicas de Uberaba - MG. A pesquisa é de natureza básica desenvolvida na abordagem qualitativa, onde utilizaremos a pesquisa de campo, cujos instrumentos serão a observação participante e entrevista semi estruturada. Os dados coletados serão analisados pela técnica análise de conteúdo. Esperamos levantar elementos que sirvam para subsidiar ações pontuais no processo de formação continuada em serviço da rede pública de ensino.

PALAVRAS-CHAVE: Formação Continuada em Serviço. Educação Básica. Identidade Docente.

\section{ABSTRACT}

The proposals for continuing education for teachers have been a concern both for the public power, as for researchers and education theorists. The present project aims to verify the effectiveness of continuing education in service in terms of conceptual advances in the constitution of the identity and practices of teachers of Basic Education of public schools in Uberaba - MG. The research is of a basic nature developed in the qualitative approach, where we will use the field research, whose instruments will be participant observation and semi structured interview. The data collected will be analyzed by the technique of content analysis. We hope to raise elements that serve to subsidize punctual actions in the process of continuing education in service of the public school system.

\section{KEYWORDS: Continuing Service Training. Basic education. Teaching Identity.}

\section{RESUMEN}

Las propuestas de formación continuada para los docentes han sido una preocupación tanto para el poder público, como para investigadores y teóricos de la educación. El presente proyecto tiene como objetivo verificar la eficacia de la formación continuada en servicio en términos de avances conceptuales en la constitución de la identidad y en las prácticas de los profesores de la Educación Básica de escuelas públicas de Uberaba - MG. La 
investigación es de naturaleza básica desarrollada en el abordaje cualitativo, donde utilizaremos la investigación de campo, cuyos instrumentos serán la observación participante y entrevista semi estructurada. Los datos recolectados serán analizados por la técnica análisis de contenido. Esperamos levantar elementos que sirvan para subsidiar acciones puntuales en el proceso de formación continuada en servicio de la red pública de enseñanza.

PALABRAS-CLAVE: Formación continua en servicio. Educación básica. Identidad Docente.

\section{INTRODUÇÃO}

A legislação das políticas Educacionais brasileiras por meio da Lei de Diretrizes e Bases da Educação Nacional, (BRASIL LDBEN - Lei no 9.394, de 20/12/1996), bem como decretos e resoluções pertinentes, dispõe sobre a importância da formação continuada sistêmica e em serviço do professor da educação básica para ações de estudo, capacitações, análises e planejamento da prática pedagógica, com o objetivo de enriquecê-la e garantir o sucesso dos alunos no processo ensino-aprendizagem.

As propostas de formação continuada para os docentes têm sido, nestes últimos anos, uma preocupação tanto para o poder público (mesmo no sentido de manter a reprodução ideológica da classe dominante), como para pesquisadores e teóricos da educação. Gatti (2003) destaca que a formação continuada de professores abarca uma dubiedade envolvendo aspectos sociais e psicológicos, em efígie da pluralidade de significados que essa tessitura abrange. Lima (2001) nos traz a seguinte reflexão sobre formação continuada: "Formação contínua é a articulação entre o trabalho docente, o conhecimento e o desenvolvimento profissional do professor, como possibilidade de postura reflexiva dinamizada pela práxis" LIMA (2001, p.30).

Enfim, temos inúmeros exemplos práticos dessa inquietude, que apesar de amplamente argumentada e granjeada, não manifestou eficácia em sua exortação. Vale destacar que nenhum profissional deve ficar estagnado ao finalizar o curso de graduação. É explicito que na área educacional existem inúmeras lacunas entre o saber universitário e a prática docente em sala de aula, por ser o professor um profissional a quem são atribuídas múltiplas e contraditórias funções, tais como formadores de opinião, preparação para o mercado de trabalho e cidadãos no seu âmbito mais amplo. Na composição desse contexto nossa prática mostra que os professores frequentam a formação continuada em serviço, demonstrando 


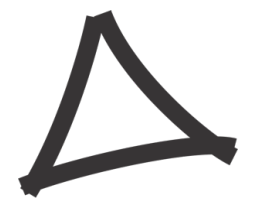

Revista Triângulo

www.seer.uftm.edu.br/revistaeletronica

descontentamento e indiferença, que atribuímos, em parte, a uma excessiva carga de responsabilidade.

Diante do exposto, optamos por investigar como a formação continuada acontece nas escolas públicas partindo da premissa de que as formações continuadas em serviço sejam um espaço de efetivação da autonomia, onde ocorra dialogicidade e ao invés de designar culpados ou justificativas amenizadoras para dilemas enfrentados, ocorra a busca coletiva de soluções concretas para os problemas experienciados no cotidiano escolar e peculiares no papel de professor exigido na contemporaneidade. Entendemos que esta perspectiva irá levar os professores a refletirem sobre a constituição de sua identidade profissional.

Buscaremos desenvolver o trabalho no âmbito de formação continuada em serviço dentro das escolas públicas, com o propósito de conhecer como se constitui a política de formação continuada de professores em relação às possibilidades e desafios encontrados em sala de aula. Dessa forma, o presente projeto orienta-se pela questão diretriz: $\boldsymbol{A}$ formação continuada em serviço possibilita um avanço nas práticas dos professores de Educação Básica das escolas públicas de Uberaba?

Este contexto traz consigo outras interrogações profícuas, descritas no quadro abaixo, já relacionado aos objetivos específicos da pesquisa.

Quadro 1- Questões de pesquisa e objetivos do trabalho

\begin{tabular}{|c|c|}
\hline Questões de pesquisa & Objetivos \\
\hline $\begin{array}{l}\text { A formação continuada em serviço possibilita } \\
\text { um avanço nas práticas dos professores } \\
\text { de Educação Básica das escolas públicas? }\end{array}$ & $\begin{array}{l}\text { Verificar a eficácia da formação } \\
\text { continuada em serviço em termos } \\
\text { de avanços conceituais nas práticas } \\
\text { dos professores de Educação Básica } \\
\text { de escolas públicas da cidade de } \\
\text { Uberaba/MG. }\end{array}$ \\
\hline $\begin{array}{l}\text { Como a formação continuada contribui para o } \\
\text { desenvolvimento da identidade docente? }\end{array}$ & $\begin{array}{lcr}\text { Averiguar como o professor que } \\
\text { participa dessa formação } & \text { se } \\
\text { reconhece } & \text { culturalmente } & \mathrm{e}\end{array}$ \\
\hline
\end{tabular}




\begin{tabular}{|c|c|}
\hline & profissionalmente \\
\hline $\begin{array}{l}\text { Do ponto de vista destes professores, que } \\
\text { formação eles consideram ideal para que haja a } \\
\text { articulação dos saberes e experiências } \\
\text { anteriormente adquiridos com novas práticas de } \\
\text { ensino-aprendizagem? }\end{array}$ & $\begin{array}{l}\text { Identificar a percepção dos professores } \\
\text { sobre a formação ideal para uma escola } \\
\text { real. }\end{array}$ \\
\hline $\begin{array}{l}\text { Nas formações em } \\
\text { professores pontuam, estudam, discutem e } \\
\text { estão cônscios da relevância da formação dos } \\
\text { professores com o trabalho pedagógico e com o } \\
\text { currículo que deve ser reconfigurado no ato } \\
\text { pedagógico pelos modos de representação e } \\
\text { produção de conhecimentos propiciados pelo } \\
\text { mundo contemporâneo? }\end{array}$ & $\begin{array}{l}\text { Verificar se a formação continuada em } \\
\text { serviço sinaliza para uma organização } \\
\text { curricular inovadora que estabeleça novas } \\
\text { relações entre a teoria e a prática. }\end{array}$ \\
\hline $\begin{array}{l}\text { Os cursos de formação, capacitação e atualização } \\
\text { criam instrumentos que viabilizam a } \\
\text { familiarização dos professores com a sua prática } \\
\text { docente? }\end{array}$ & $\begin{array}{l}\text { Investigar a existência de ferramentas que } \\
\text { levem o professor a uma atuação, em sala } \\
\text { de aula, comprometida com as } \\
\text { transformações sociais contemporâneas. }\end{array}$ \\
\hline $\begin{array}{l}\text { O Projeto Político Pedagógico (PPP) da } \\
\text { escola contempla a formação continuada } \\
\text { em serviço? De que forma ela está } \\
\text { inserida e qual é a linha dessa inserção? }\end{array}$ & $\begin{array}{l}\text { Verificar se nas formações em serviços, } \\
\text { estudos são elaborados a partir de um } \\
\text { referencial teórico que faz parte do projeto } \\
\text { político pedagógico da escola e se o PPP } \\
\text { contempla uma filosofia que atenda aos } \\
\text { professores nessa perspectiva. }\end{array}$ \\
\hline $\begin{array}{l}\text { Quem é o protagonista das ações, métodos e } \\
\text { avaliações das formações continuadas em }\end{array}$ & $\begin{array}{l}\text { Identificar o centro das ações formativas } \\
\text { na escola }\end{array}$ \\
\hline
\end{tabular}




\begin{tabular}{|l|l|}
\hline serviço? & \\
\hline Qual o olhar do professor sobre os novos & $\begin{array}{l}\text { Examinar a evidência de uma cultura } \\
\text { espaços de apoio aberto aos professores através } \\
\text { dos ambientes virtuais de aprendizagem? }\end{array}$ \\
& $\begin{array}{l}\text { prática interdisciplinar e contextualizada } \\
\text { com o domínio de inovadoras tecnologias } \\
\text { educacionais. }\end{array}$ \\
\hline
\end{tabular}

Cumprindo com esses objetivos, buscamos levantar dados que venham discutir a visão dos docentes da Educação Básica da escola pública no que se refere à formação continuada em serviço e à transformação de suas práticas escolares, adequando a escola a seu tempo. Esta reflexão dos docentes poderá subsidiar uma reformulação curricular para incorporá-la ao contexto social atual, buscando responder de que forma isso ocorre dentro da formação continuada em serviço.

\section{REFERENCIAL TEÓRICO}

$\mathrm{Na}$ atualidade buscamos romper com o modelo de formação baseada na racionalidade técnica, em que o professor é visto com uma formação pautada na educação bancária (FREIRE, 1987, p.33), na qual o aluno recebe conhecimentos e deve devolvê-lo, ou seja, dar um retorno, na maioria das vezes através da memorização, que é arcaica, principalmente depois da chegada da cultura digital e da globalização, fato que acelera a crise da identidade do professor. Nesse entrecho o uso das tecnologias digitais é colocado como uma das formas de experiência educativa que busca dinamizar o processo ensinoaprendizagem, inserindo mais um dilema na prática do professor e em sua formação inicial e continuada. Enfim, a falta de preparação e qualificação para o trabalho pode ser um dos motivos que os condiciona a seguir modelos educativos ineficazes e transmitir conhecimentos descontextualizados, embasados em resultados esperados pelo MEC (Ministério da Educação e Cultura). Na visão de Pimenta: 


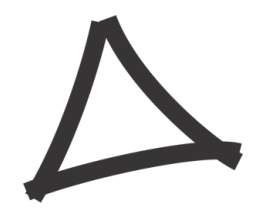

Revista Triângulo

www.seer.uftm.edu.br/revistaeletronica

A formação de professores reflexivos compreende um projeto humano emancipatório. [...] as escolas de formação de professores necessitam ser reconhecidas como esferas contrapúblicas, de modo a propiciarem a formação de professores com consciência e sensibilidade social. Para isso, deve educá-los como intelectuais críticos capazes de ratificar e praticar o discurso da liberdade e da democracia. (PIMENTA, 2012, p.31).

Aparentemente esperamos que os professores da sociedade contemporânea sejam capazes de ajudar a compor a endrômina do desenvolvimento individual e coletivo e que saibam manejar os instrumentos que a cultura indica como representativos de modos de viver e de pensar civilizados, específicos da hodiernidade e do futuro.

As professoras ensinam em escolas cuja forma básica foi definida nos séculos XVI e XVII; um espaço segmentado, um tempo fragmentado, uma avaliação que diz o valor da pessoa do aluno. Essa forma escolar condiz com a pedagogia tradicional. É nela que a professora é convidada a ser construtivista e a usar o computador e a internet... (CHARLOT, 2008, p.26).

Simultaneamente a esses entraves, verificamos um paradoxo na concretização das formações de professores: as dificuldades da escola em utilizar da hora-atividade para a realização de grupo de estudos e reflexão docente.Somados às dificuldades de buscar soluções para minimizar esses problemas, há falta de interesse, de tempo, de comprometimento de muitos professores e a rejeição à maioria dos cursos, seminários, simpósios, bem como a outras modalidades de formação continuada oferecidas por instituições diversas. Além destes obstáculos à formação continuada, deve-se salientar o fato de que cada instituição educacional tem suas particularidades e a formação oferecida nem sempre vai ao encontro da realidade vivenciada em diferentes ambientes educacionais nos quais os docentes atuam. Diante deste contexto, acreditamos que a formação continuada realizada na própria escola seja uma das alternativas para a melhoria da qualidade do processo ensino-aprendizagem. No entanto, salientamos que em muitos casos as reuniões administrativas são integradas às reuniões de formação em serviço, prevalecendo as pautas da primeira em detrimento da segunda.

Partindo do pressuposto de que o saber empírico por nós vivenciado em escolas públicas nas quais trabalhamos, aliado ao saber cientifico, poderia levar ao descortinar de incertezas e ansiedades, no que se refere à formação continuada em serviço, resolvemos 


\section{$\Delta$}

investigar os fatores que levam seus atores à indiferença e quase desprezo pelas formações em serviço e, se de fato elas têm contribuído com os professores em sua prática.

Evidenciamos que a nossa prática como docente em escolas públicas mostra que é nítida a insatisfação do professores e formadores ao observarmos uma formação continuada em serviço. A grande maioria demonstra ter participado por obrigação e deixa claro que aquela experiência não acrescentou nada positivo à sua prática docente, não ocorrendo diálogo e interação entre as partes. Alguns chegam a ver nos formadores a figura do opressor e parecem sentir necessidade de libertação de toda a carga depositada sobre seus ombros pelo sistema, muitas vezes já cansado de lutar uma luta inglória, visto que as políticas públicas, e até mesmo a sociedade, não lhes dão o valor que se acham merecedores. Alvarado Prada relata que:

É comum observar como na "qualificação" de docentes, estes são informados de conceitos teóricos que pouco lhes interessam e, até por isso, não compreendem nem veem aplicabilidade. Em consequência, produzem formas de resistência e criam conceitos meramente mecanicistas e utilitários da "qualificação" que, ao invés de melhorar o exercício dos docentes, os desmotiva, dificultando as mudanças e o despertar de novos interesses em tal sentido. (ALVARADO PRADA, 1997, p.102).

Portanto, é necessário que seja oportunizado a esse professor um espaço no qual a homologia dos professores com seus próprios saberes e suas relações identitárias possam dialogar, se conectando às novas facetas do modo de aprender dos educandos, possibilitando a expressão de sua voz.

Por meio de todas as tecnologias e bibliografias acessíveis, dispomos de inúmeras possibilidades em termos de apropriação do conhecimento. SAVIANI (2003, p.75) afirma que "a escola tem papel de possibilitar o acesso das novas gerações ao mundo do saber sistematizado, do saber metódico, científico.” Essas transformações sociais exigem mudanças na educação, que por sua vez requer mudanças na postura dos educadores. Entendemos que mudanças na postura dos educadores passam por programas bem elaborados de capacitação profissional. Vislumbramos a educação como o caminho para as transformações sociais e, para que isso aconteça, precisa-se de educação comprometida, de qualidade, atualizada e contextualizada. Faz-se necessário, portanto, ensinar a aprender. Segundo RODRIGUEZ e SILVA (2015): 


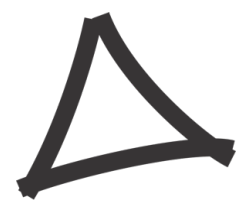

... a partir de 2006, a política de formação de professores existente, desarticulada e fragilizada na década de 1990, sofreu um reposicionamento da esfera federal, consolidando uma tendência à recentralização/concentração nas políticas públicas federais de formação de professores. $\mathrm{O}$ processo em destaque realiza uma recentralização na União e uma concentração da política nacional de formação no Ministério da Educação (MEC).

Nessa perspectiva a educação começou a ser gerenciada com um modelo empresarial, na busca de resultados, levando para as formações continuadas, principalmente em serviço, uma tensão e apreensão induzindo formadores e professores à condução de formações e práticas educativas que buscam atender às expectativas quantitativas esperadas pelo poder público. COSTA (2004) expõe: “A formação contínua constitui ainda condição de progressão na carreira". Rodriguez e Silva (2015), em seu artigo, reportam, também, uma inquietação dos professores no que se refere às decisões e orientações que vêm sempre dos gabinetes e não contemplam a voz dor professor.

Pimenta (2012) contrapõe-se às correntes de desvalorização dos professores, entendendo que na atual sociedade, cada vez mais esse profissional é necessário, não como um reprodutor de conteúdos, mas como mediador nos processos que constituem o caráter cidadão do aluno. Essa valorização do professor, conforme esta autora, perpassa a necessidade de repensar a formação inicial e continua dos professores. $\mathrm{O}$ autor ressalta que a importância dessa mediação está representada nas ações dos professores, dos discentes, dos pais, das políticas curriculares, das organizações educacionais, dos sistemas de ensino e das inovações educativas.

Quanto às tecnologias da informação e à formação de professores, Alonso (2008), enfatiza a contradição da crença de que a escola fundamental e média seja a extensão do mundo economicamente produtivo e que venha atender à demanda do mercado. As políticas públicas distribuem equipamentos, anunciam a necessidade de inovação e jogam essa demanda para a responsabilidade dos professores (Josgrilberg, 2006). "Transfere-se, desse modo, para as "mãos" dos envolvidos diretamente com as práticas escolares/pedagógicas a empreitada da transformação, cabendo-lhes recriar fazeres e saberes de lógicas estranhas e alheias a seu cotidiano"ALONSO (2008, p.756). 


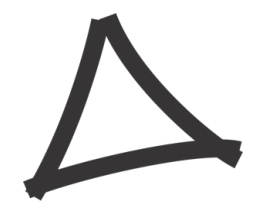

Revista Triângulo

www.seer.uftm.edu.br/revistaeletronica

Na concepção de Tardif (2014), existem múltiplos saberes e mesmo sendo a prática do professor individual, ela reflete as relações que instaurou durante sua vida a respeito de suas ações. Tudo isso deve ser considerado em uma formação continuada: a família, a escola, o meio cultural de origem, a formação institucional básica e acadêmica. Enfim, todos os fatores mencionados acima interferem na prática do professor.

CARDOSO, DEL PINO e DORNELLES (2012, p. 54), relatam que:

Tardif discorre a respeito dos saberes docentes e a sua relação com a formação profissional dos professores e ainda com o próprio exercício da docência. Destaca, a partir de pesquisas realizadas com o propósito de compreender o que pensam os professores sobre os seus saberes, que o saber docente é um "saber plural, formado de diversos saberes provenientes das instituições de formação, da formação profissional, dos currículos e da prática cotidiana.

Cremos que a formação em uma perspectiva humanizada é possível, como formar para um mundo sustentável, para uma educação emancipadora, para a ruptura com o individualismo das classes dominantes, bem como para mediar as inovações contemporâneas.

\section{MATERIAIS E MÉTODOS}

\section{Tipo de pesquisa}

O presente estudo é de natureza básica desenvolvida na abordagem qualitativa, na qual utilizaremos a pesquisa de campo cujos instrumentos serão a observação participante e a entrevista semi-estruturada.

Optamos pela abordagem qualitativa partindo da concepção de que nossa pesquisa envolve questões e significados sociais e culturais. Assim sendo, teremos maior liberdade de analisar e interpretar de forma subjetiva nosso objeto de estudo e, por se tratar de um trabalho que envolve questões relacionadas a outros seres humanos, diligenciaremos assegurar um processo proficiente e ético.

Flick (2009) afirma que a pesquisa qualitativa não se baseia em um único conceito teórico e metodológico e que os pontos de vista subjetivos são um escopo inicial da pesquisa.

Os aspectos essenciais da pesquisa qualitativa consistem na escolha adequada de métodos e teorias convenientes; no reconhecimento da análise de diferentes 


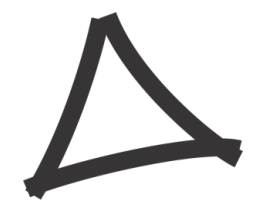

Revista Triângulo

www.seer.uftm.edu.br/revistaeletronica

perspectivas; nas reflexões dos pesquisadores a respeito de suas pesquisas como parte do processo de produção de conhecimento; e na variedade de abordagens e métodos. (FLICK, 2009, p. 23).

\section{Sujeitos e local de pesquisa}

Faremos o trabalho de campo em duas escolas públicas da cidade de Uberaba/MG, sendo uma estadual e a outra municipal.

Em nossa atuação utilizaremos as técnicas que, segundo nossa ótica, melhor se adequarão ao processo que vamos empreender: observação participante e entrevista semiestruturada.

As entrevistas serão aplicadas em dez sujeitos, sendo cinco de cada escola que serão escolhidos por meio de amostragem não probabilística, por conveniência.

A observação participante será feita com todos os professores envolvidos na formação continuada em serviço nas referidas escolas.

\section{Instrumentos}

Utilizaremos observação participante devido à praticabilidade de um contato direto com o objeto de investigação, o que nos permitirá depreender os significados que outorgam à sua realidade e às suas ações, através do acompanhamento de suas vivências. A observação participante consistirá em recolher e registrar os fatos da realidade sem a utilização de meios técnicos especiais (MARCONI e LAKATOS, 2002).

A entrevista será outra técnica utilizada, pois tem como objetivo obter respostas que contribuam de maneira significativa e contundente para nosso objeto de estudo. MINAYO (2002, p.96) afirma que: "Entrevista exige habilidade e sensibilidade; não é tarefa fácil, mas é básica. Quando o entrevistador consegue estabelecer certa relação de confiança com o entrevistado, pode obter informações que de outra maneira talvez não fossem possíveis.”

\section{Procedimentos}

Entraremos em contato com os responsáveis pelas instituições escolares nas quais a pesquisa será realizada e, assim que obtivermos sua autorização por escrito e devidamente assinada, daremos início à coleta de dados. Em seguida buscaremos junto à direção o

\begin{tabular}{l|l|l|l|l|l|l|} 
(C) Rev. Triang. & Uberaba, MG & v.11 & n.1 & p. 33-47 & Jan./Abr. 2018 & ISSN 2175-1609
\end{tabular}




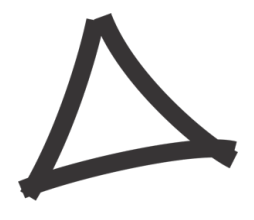

calendário de formações continuadas em serviço, para procedermos com a observação participante.

Na primeira formação de cada escola, faremos uma apresentação do nosso objeto de pesquisa, salientando a altercação ética que prevalecerá em todos os passos dados por nós no desenvolvimento desse trabalho, cuja abordagem será neutra e investigativa, na busca de contribuir cientificamente na compreensão de como se dão as formações em serviço nas escolas públicas de Uberaba e de como os professores se percebem nessa conjuntura. $\mathrm{Na}$ ocasião salientaremos que será dada uma devolutiva aos participantes, no encerramento de nosso projeto. Após todos estarem cônscios do nosso objetivo e aceitarem nossa presença, iniciaremos a observação participante. Será elaborado um diário de observações para cada uma das escolas, buscando não "deixar escapar” minúcias que podem ser significativas no momento da análise dos dados. Posteriormente faremos uma entrevista piloto buscando compor de maneira mais assertiva nossas questões da entrevista semiestruturada. As perguntas iniciais poderão ser aprimoradas a partir de nossas observações dentro do ambiente de pesquisa, norteadas por nosso objetivo geral e objetivos específicos, sempre no enfoque do objeto de estudo por nós proposto. Concluída a fase de observação participante, selecionaremos os sujeitos que participarão da entrevista semi-estruturada, ratificando que serão cinco em cada escola, cuja escolha será pela abordagem não probabilística. Serão convidados professores que tenham maior disponibilidade para nos conceder as entrevistas, que possam contribuir de forma efetiva para a pesquisa. Vale ressaltar que, conforme FONTANELLA, LUCHESI, SAIDEL, RICAS e TURATO, MELAM (2011, p.389):

"Fechar" a amostra significa definir o conjunto que subsidiará a análise e interpretação dos dados. Nas amostras não-probabilísticas (intencionais), tal definição é feita a partir da experiência do pesquisador no campo de pesquisa, numa empírica pautada em raciocínios instruídos por conhecimentos teóricos da relação entre objeto de estudo e o corpus a ser estudado.

O número inicial de sujeitos poderá sofrer alteração, para menos ou para mais, levando em consideração o processo de saturação teórica, embasados em FONTANELLA, RICAS e TURATO(2008, p.20), que apontam:

A avaliação da saturação teórica a partir de uma amostra é feita por um processo contínuo de análise dos dados, começando já no início do processo de coleta. Tendo em vista as questões colocadas aos entrevistados, que refletem os objetivos da pesquisa, essa análise preliminar busca o momento 


\section{$\Delta$}

em que pouco de substancialmente novo aparece, considerando cada um dos tópicos abordados (ou identificados durante a análise) e o conjunto dos entrevistados.

Para tanto os autores acima citados nos orientam seguir as seguintes etapas: mergulhar nos registros gravados e redigidos de cada entrevista para que possamos refletir e tirar deles o enunciado ou tema, cerzir os temas e enunciados, estando atento ao momento da entrevista em que esses foram colhidos. Deve-se agrupá-los em categorias, constando os trechos condensados ou identificados e nomear cada categoria de acordo com o que ela representa em seu conjunto.

Nomear algo que anteriormente não tinha nome revela as inclinações teóricoideológicas dos pesquisadores, podendo este procedimento ser revisto continuamente, de acordo com os aprofundamentos conceituais que se processem no estudo adicional e na discussão. Não se trata de vincular imediatamente a denominação escolhida a determinada teoria. Embora se considere que nomear seja uma atitude expressiva do pensamento, reveladora dos conhecimentos de quem nomeia, mesmo que o pesquisador conheça profundamente certas teorias, poderá mantê-las temporariamente em suspensão (atitude próxima à epochê dos fenomelogistas) para evitar uma possível ilusão de transparência. (FONTANELLA, RICAS e TURATO, 2008, p.20).

Em seguida os dados serão alocados em uma tabela que nos permitirá uma melhor visualização dos temas e enunciados para que possamos, assim, constatar e descortinar a saturação teórica.

\section{ANÁLISE DOS DADOS E RESULTADOS}

\section{Análise de dados}

A análise de dados é um decurso de procura e de organização de registro de campo, transcrição de entrevistas, opiniões e inferências do pesquisador que serão manuseados objetivando estender o entendimento do pesquisador. Esse procedimento será feito durante todo o processo da pesquisa, pois há a probabilidade de que anotações, reflexões e respostas das entrevistas nos levem a novos questionamentos e novas observações.

Os dados coletados nas entrevistas e nas observações participativas serão analisados pela técnica de Análise de Conteúdo na qual, segundo BARDIN (1977, p. 34):

O analista é um arqueólogo. Trabalha com vestígios: os $<<$ documentos $>>$ que pode descobrir ou suscitar. Mas os vestígios são as manifestações de estados, de dados e de fenômenos. Há qualquer coisa para descobrir e graças a eles. Tal como a etnografia

\begin{tabular}{l|l|l|l|l|l|l|} 
(C) Rev. Triang. & Uberaba, MG & v.11 & n.1 & p. 33-47 & Jan./Abr. 2018 & ISSN 2175-1609
\end{tabular}




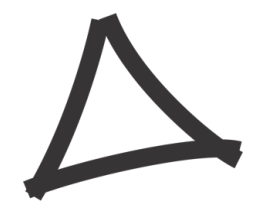

Revista Triângulo

www.seer.uftm.edu.br/revistaeletronica

necessita da etnologia para interpretar as suas descrições minuciosas, o analista tira partido do tratamento das mensagens que manipula para inferir (deduzir de maneira lógica) conhecimentos sobre o emissor da mensagem ou sobre seu meio, por exemplo.

\section{Situação atual da pesquisa}

A fim de um melhor planejamento das ações a serem desenvolvidas durante a pesquisa, foi elaborado um plano de trabalho, onde: realizamos um levantamento bibliográfico na fase exploratória do projeto buscando autores que dialogassem com nosso objeto de pesquisa e, a partir deles, fizemos nosso marco teórico. Também fundamentamos nossa pesquisa em autores que discorrem sobre o tema e assuntos propostos, definindo uma base teórica e conceitual que nos possibilitasse formular hipóteses e problematização. Posteriormente nos dirigimos até as escolas onde faremos o trabalho de campo e, após uma interlocução com a direção das mesmas, nos foi possibilitado o acesso a elas.

Atualmente estamos em processo de interação com os professores das instituições educacionais. O passo seguinte será iniciar a observação participante, visto que o calendário com a data das formações já nos foi passado. Continuamente, estamos aprofundando nosso conhecimento científico para a construção do roteiro das entrevistas semi-estruturadas.

\section{CONSIDERAÇÕES FINAIS}

Foi verificado durante a revisão bibliográfica que a formação continuada em serviço deve cumprir seu objetivo de agregar conhecimentos aos profissionais da docência, suprindo carências da formação inicial e também ajudando a resolver as dificuldades que surgem no enfrentamento dos desafios do atendimento da diversidade na sala de aula. E que o professor precisa de apoio e não pode ser o único a ser responsabilizado pelo fracasso ou dificuldade dos estudantes.

Sendo assim, aumentamos a convicção de que este trabalho de pesquisa é relevante e trará contribuições para uma melhor compreensão e aperfeiçoamento da prática de formação de professores em serviço nas escolas públicas de Uberaba-MG. 


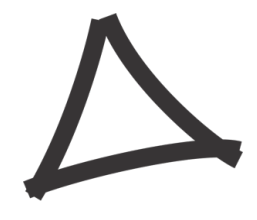

\section{REFERÊNCIAS}

ALONSO, K. M.; Tecnologias da informação e comunicação e formação de professores: sobre rede e escolas. Educ. Soc. [online]. 2008, vol. 29, n.104, p. 747-768. Disponível em: http://www.scielo.br/pdf/es/v29n104/a0629104.pdf, acessado em 20 de julho de 2017.

ALVARADO PRADA, Luis Eduardo. Formação Participativa de docentes em Serviço. Cabral Editora Universitária, 1997.

BARDIN, Laurence. Análise de Conteúdo. Edições 70- Almedina, 2011.

BRASIL. Lei de Diretrizes e Bases da Educação Nacional. Lei número 9394, 20 de dezembro de 1996.

BRASIL, Secretaria de educação Fundamental, PCN: terceiro e quarto ciclos do ensino fundamental: Introdução aos parâmetros curriculares nacionais. Brasília: MEC/SEF, 1998 p. 174

CARDOSO, Aliana A.; DEL PINO, Mauro A. B.; DORNELES, Caroline L. Os saberes profissionais dos professores na perspectiva de Tardif e Gauthier: contribuições para o campo de pesquisa sobre os saberes docentes no Brasil. IX AMPED SUL, 2012. Disponível em http://www.ucs.br/etc/conferencias/index.php/anpedsul/9anpedsul/paper/viewFile/668/556. Acessado em junho 2015, acessado em maio de 2017.

CHARLOT, Bernard. O Professor na sociedade Contemporânea: Um Trabalhador da Contradição. FAEEBA - Salvador, v. 17, n.30, p. 17-31, jul./dez. 2008.

COSTA, Marisa Vorraber. Quando o pós-moderno invade a escola: um estudo sobre novos artefatos, identidades e práticas culturais. Projeto de pesquisa apoiado pelo CNPq. (2004-2007), 2004. 
FLICK, Uwe. Introdução a Pesquisa Qualitativa, 3 ed. Tradução: Joice Elias Costa Porto Alegre: Artemed, 2009.

FONTANELLA, Bruno J. B.; LUCHESI, Bruna M.; SAIDEL, Maria G. B.; RICAS, Janete; TURATO, Egberto R.; MELO, Débora G. Amostragem em pesquisas qualitativas: proposta de procedimentos para constatar saturação teórica. Cad. Saúde Pública, Rio de Janeiro, 27(2): 389-394, fev, 2011.

FONTANELlA, Bruno J. B.; RICAS, Janete; TURATO, Egberto R.; Amostragem por saturação em pesquisas qualitativas em saúde: Contribuições Teóricas. Cad Saúde Pública. Rio de Janeiro, janeiro 2008.

FREIRE, P. Educação como Prática de Liberdade. Rio de Janeiro: Paz e Terra, 1987.

GATTI Bernadete. Formação continuada de professores: a questão psicossocial. Cadernos de Pesquisa, São Paulo, n. 119, p. 191-204, julho 2003.

LIMA, Maria Socorro Lucena. Memorial de formação. Fortaleza: UECE - Centro de Educação, 2001.

MARCONI, M.A LAKATOS, E.M. técnicas de pesquisa. 7 ed. São Paulo, Atlas, 2010.

MINAYO, MC. Souza. Teoria, Método e Criatividade. 21 Edição. Editora Vozes, 2002.

PIMENTA, Selma Garrido. Formação de professores: identidade e saberes da docência. In (org) Saberes pedagógicos e atividade docente. 8ed. São Paulo: Cortez, 2012.

RODRIGUEZ, Vicente e SILVA, Domingos Pereira da. Formação continuada em serviço em contextos descentralizados. Cad. CEDES [online]. 2015, vol.35, n.97, pp.553-574. ISSN 0101-3262.

SAVIANI, Demerval. Educação e questões da atualidade, São Paulo, Cortez, 2003, p.75.

TARDIF, Maurice. Saberes docentes e formação profissional. 17 ed. - Petrópolis, Rj: Vozes, 2014. 